\title{
EL PROCESAMIENTO DE BALLENAS VARADAS EN LAS COSTAS DE LA PATAGONIA OCCIDENTAL [A PROPÓSITO DE UN GRABADO DE MEDIADOS DEL SIGLO XIX]
}

\author{
DANIEL QUIROZa ${ }^{\mathrm{a}}$ GASTÓN CARREÑO ${ }^{\mathrm{b}} \&$ PAULA DE LA FUENTEc
}

\begin{abstract}
RESUMEN
Para los canoeros del extremo sur americano la varazón de una ballena era "un gran regalo de la naturaleza”. La noticia de su presencia, en algún punto de la costa patagónica, se trasmitía rápidamente y la gente llegaba desde lugares muy lejanos para compartir sus productos. En este trabajo analizamos la información etnográfica proporcionada por un grabado del siglo XIX que muestra "una inusual pero práctica manera de conducir los bloques de tocino de ballena a tierra firme". El grabado fue publicado por el novelista inglés Thomas Mayne Reid en su obra Odd People (1860) pero la información original proviene de los textos generados por las expediciones del H.M.S. Beagle en las costas fuego-patagónicas entre 1831 y 1836 . Hacemos algunas observaciones sobre el contexto en el que aparece la "costumbre fueguina" de trasladar trozos de grasa de ballena sobre la cabeza.
\end{abstract}

PALABRAS CLAVES: ballenas varadas, fueguinos, Capitán Thomas Mayne Reid, expedición del H.M.S. Beagle, Siglo XIX.

\section{STRANDED WHALES PROCESSING IN THE WESTERN PATAGONIAN SHORES [FROM AN ENGRAVING OF MID-NINETEENTH CENTURY]}

\begin{abstract}
For canoe peoples of southernmost American, the stranding of a whale was "a great gift of nature". The news of his presence, somewhere along the Patagonian coast, was transmitted very fast and people came from far places to share their products. In this paper we analyze the ethnographic information provided by a nineteenth-century engraving showing "an unusual yet ultimately practical way of carrying slippery blocks of whale blubber ashore". The engraving was published by English novelist Thomas Mayne Reid in his Odd People (1860), but the original information is in the texts generated by the expeditions of HMS Beagle in Fuego-Patagonian coast between 1831 and 1836. We make some

a Centro de Documentación de Bienes Patrimoniales, Dirección de Bibliotecas, Archivos y Museos. Recoleta 683, Recoleta, Santiago. Proyecto Fondecyt 1140056. daniel.quiroz@museosdibam.cl.

b Centro de Estudios en Antropología Visual. Proyecto Fondecyt 1140056. gaston.carreno@ceavi.cl.

c Proyecto Fondecyt 1140056. paulastranger@gmail.com.
\end{abstract}


observations about the context in which the "fuegian custom" of carrying pieces of blubber on the head appears.

KEY WORDS: stranded whales, fuegians, Captain Thomas Mayne Reid, H.M.S. Beagle's expedition, XIX Century.

Desde hace algunos años se ha estado desarrollando un programa de investigaciones sobre las relaciones entre los grupos humanos y las ballenas en las costas de Chile. En este marco se generó una línea de trabajo respecto del aprovechamiento de cetáceos varados y la eventual caza de ballenas entre los pueblos originarios que habitaban/habitan los archipiélagos australes, antes y después de la llegada de los europeos. Se ha recopilado una abundante información textual relevada por viajeros, exploradores, misioneros y científicos que estuvieron en contacto con estos pueblos y también algunos relatos que han elaborado, a partir de ella, algunos naturalistas, historiadores y novelistas. La información visual, sin embargo, es escasa.

El principio que orienta este programa es el de la etnografía retrospectiva, es decir, un enfoque que intenta estudiar un modo de vida del pasado como si fuera contemporáneo, utilizando "los mejores equivalentes históricos de las observaciones de los etnógrafos", para que ese modo de vida reconstituido sirva "como contexto para una explicación de la acción colectiva" (Tilly, 1978, p. 210). En esta línea se analizará uno de los pocos testimonios visuales que existen sobre el aprovechamiento de ballenas varadas entre los pueblos canoeros del extremo sur americano. Interesa, sobre todo, contextualizarlo y evaluar su relevancia para el conocimiento de una costumbre específica: un modo particular de trasladar los restos de una ballena varada para su posterior consumo.

\section{EL PROCESAMIENTO DE BALLENAS VARADAS}

El encuentro con una ballena varada pudo

1 Los cazadores pedestres del extremos sur, los onas $u$ selk'nam, también aprovechaban intensivamente las ballenas varadas (Massone \& Prieto, 2005, pp. 28-29), pero en esta oportunidad no nos ocuparemos de ellos.

2 En la segunda mitad del siglo XIX, incluso a comienzos del siglo XX, se usaba el término fueguinos para nombrar a los nativos de Tierra del Fuego, es decir, "yaganes en el sur, alacalufes en el oeste y onas en el este"; siendo considerados los dos primeros grupos "indios canoeros", pues "pasan la mayor parte de su tiempo en el agua" (Cooper, 1917, p. 2). ocurrir desde que los grupos humanos comenzaron, hace varias decenas de miles de años, a vivir cerca de las costas: "una ballena muerta era un golpe de suerte; proporcionaba generosas reservas de comida y grasa; tendones para coser la ropa y elaborar líneas de pesca; y huesos para hacer casas, muebles, herramientas, armas y botes" (Lazarus, 2006, pp. 21-22). Para los canoeros del extremo sur americano, la varazón de una ballena era "un gran regalo de la naturaleza" (Chapman, 2012 , p. 81)1. Las ballenas "son repetidamente mencionadas en la literatura temprana como un suministro de grandes cantidades de comida y grasa y como fuente importante de materias primas" para las poblaciones fuego-patagónicas (Piana, 2005, p. 124). La noticia de la presencia de una ballena en algún punto de la costa, hacía que se viajara desde lugares muy lejanos para compartir todos sus productos (Furlong, 1917; Lothrop, 1924). Con un solo ejemplar "se abastece a muchas familias durante varias semanas; su carne y aceite huesos y tendones, barbas y dientes tienen un útil y variado aprovechamiento" (Gusinde, 1951, pp. 212213). Para los diferentes grupos que habitaban los archipiélagos australes, "la varadura de una ballena era pretexto de fiestas y danzas" (Emperaire, 1963, p. 122). Las familias "acampaban preferentemente en las cercanías y se entregaban a una desenfrenada comilona" (Gusinde, 1991, I, pp. 299-300). Una ballena varada o muerta "era tomada con entusiasmo tanto por los fueguinos ${ }^{2}$ como por los chonos" (Cooper, 1917, p. 190).

La información etnográfica sobre el aprovechamiento de ballenas varadas entre los

\footnotetext{
Los grupos chonos, que vivían al norte de los alacalufes, entre el archipiélago de Chiloé y la península de Taitao, serían también "indios canoeros", pero no fueguinos (Cooper op.cit.: 30). Los nombres utilizados para distinguir estos grupos se han modificado una y otra vez. La Comisión de Verdad Histórica y Nuevo Trato ha institucionalizado el uso de los nombres "yaganes" y "kawésqar" para denominar a los grupos canoeros meridionales (Comisionado Presidencial para Asuntos Indígenas, 2008, p. 503, p. 515). Usaremos esta última terminología para referirnos a estos grupos.
} 
fueguinos es numerosa y variada. Martín Gusinde, quién, de una manera u otra, la recopila y une en un relato, señala que los yaganes se acercan a la ballena "y cortan grandes trozos de grasa del cuerpo del animal que llevan a la costa en sus botes" (Gusinde, 1986, I, p. 501), pero generalmente arrastraban la ballena a tierra:

cada hombre asesta su gran arpón profundamente en su cuerpo y desenrolla la larga

cuerda [...]; cada mujer guía su propia canoa en dirección a la costa más cercana, mientras que los hombres tiran detrás de sí la ballena con el lazo desenrollado [...]; si se hallan reunidas unas veinte canoas y la corriente maritima ayuda en forma considerable, este extraño convoy se aproxima a la orilla más cercana [...] se espera la aparición de una marejada o marea alta que arroje la ballena a la costa con un golpe poderoso. Pueden transcurrir días enteros hasta que esto ocurra (Gusinde, 1986, p. 501).

Algo parecido ocurre entre los kawésqar, quiénes "reunía[n] una veintena de embarcaciones, haciendo un total de cincuenta hombres, o más, alrededor del gigantesco animal. Su ocupación consistía en clavarle profundamente, uno después de otro, sus grandes arpones y retener en lo posible sus largas cuerdas de cuero". Cada hombre tiraba de su cuerda "con un fin determinado: llevar el enorme cuerpo del animal hacia la costa. Trataban de subir con la marea, lo más arriba posible de la playa el cuerpo de la ballena" (Gusinde, 1991, I, p. 299).

3 Hay 105 menciones en el diccionario para la categoría "ballenas y delfines", sólo superada por la categoría "peces", con 327 y "mariscos", es decir, moluscos y crustáceos, con 304.

4 Klaus Barthelmess fue un verdadero pilar para nuestro programa de investigación sobre la caza de ballenas en las costas de Chile. Este trabajo es un homenaje y símbolo de agradecimiento por su decidido apoyo. Klaus fallece el 18 de febrero de 2010 en su casa de Colonia, Alemania, víctima de un ataque al corazón.

5 Thomas Mayne Reid nació el 4 de abril de 1818 en Ballyroney, Irlanda. En 1840 emigra a Nueva Orleans y luego se establece como periodista en Filadelfia (1843). Sirve en el ejército
Martin Gusinde señala que los yaganes tienen "una palabra específica, ufkáriteka, para [nombrar] el lugar donde una ballena fue arrojada a la orilla" (1986, I, p. 560). Bridges, sin embargo, indica que ufkariteka significa "tener ballenas, tener abundancia de alimentos" y que la palabra ufkáritekusi designa "el lugar o región donde hay una ballena varada" (1933, p. 119).

En el diccionario yagán-inglés de Th. Bridges (1933) se manifiesta en forma muy clara la importancia de las ballenas en la vida cotidiana de los fueguinos, si consideramos la cantidad de palabras relacionadas con ellas que aparecen (Swensen, 2014, apéndice A) ${ }^{3}$. Disponer de una ballena no solo era "tener abundancia de alimentos", sino también "era signo de riqueza" y en ese sentido, para los yaganes, "la ballena era el alimento más importante" (Swensen, 2014. p. 74).

\section{EL GRABADO}

Klaus Barthelmess, un estudioso de la caza de ballenas y también coleccionista compulsivo ${ }^{4}$, nos envió a mediados del año 2009 la fotografía de un grabado que muestra a un grupo de "canoeros" transportando sobre sus hombros lo que parecen ser trozos de carne o grasa de una ballena varada (Fig. 1). La imagen es notable y una fuente de información muy valiosa, dada la escasez de representaciones visuales sobre "la vida cotidiana" entre los grupos fueguinos.

El grabado aparece impreso por primera vez en una obra escrita por el novelista inglés Thomas Mayne Reid ${ }^{5}$ titulada Odd people. Being a popular description of singular races of man $^{6}$, es decir, algo así como Pueblos Extraños. Hacia una descripción popular de las razas singulares del

de los Estados Unidos durante la Guerra Mexicana (1847), siendo seriamente herido. Regresa a Inglaterra en 1849, desarrollando en Londres una intensa vida literaria. Su vigoroso estilo encantaba a sus lectores por lo que sus libros fueron muy populares. Reid regresa a New York en 1867 donde funda el Onward Magazine, que fue del gusto de los jóvenes estadounidenses. Regresa a Inglaterra en 1870 y muere en Londres el 22 de octubre de 1883. Escribió alrededor de setenta y cinco novelas de aventuras (Steele, 1978).

6 La obra fue publicada desde 1876 con otro título: The man-eaters and other odd people: a popular description of singular races of man por James Miller Publishing, de Nueva York. 


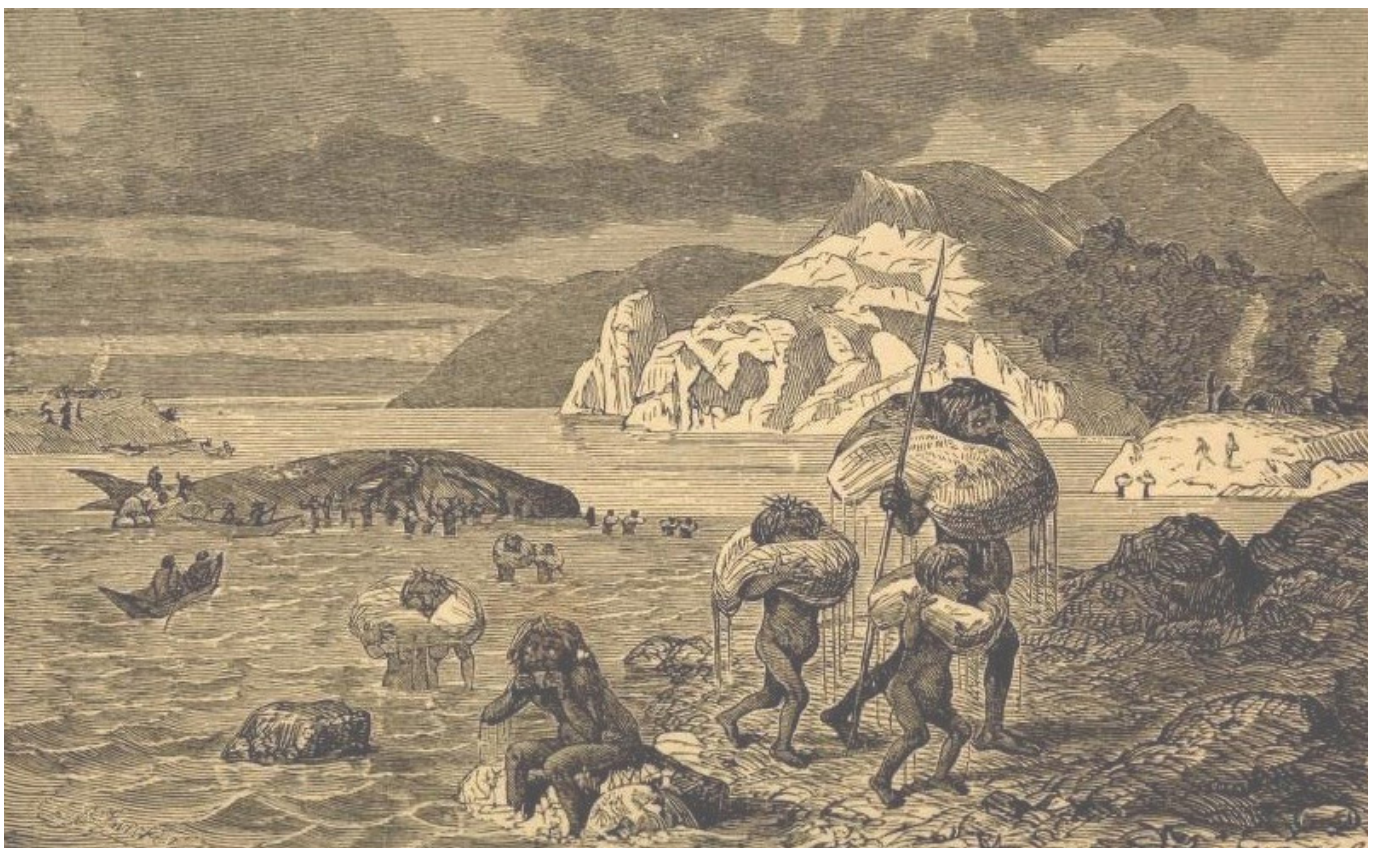

Fig. 1. El aprovechamiento de una ballena en Tierra del Fuego. Grabado en madera, 8.2 x 12,8 cm., 1860 [Colección Klaus Barthelmess, Colonia, Alemania, N 1234; En Mayne Reid, T., 1860, p. 424; grabado de J.B. Zwecker \& Dalziel Brothers].

hombre, que fue publicada en Nueva York, Estados Unidos, en 1860. El libro consta de 18 capítulos, cada uno dedicado a un grupo cultural específico. Desfilan en sus páginas bosquimanos, esquimales, comanches, turcomanos, pehuenches, lapones y patagones, entre otros. Algunos capítulos están ilustrados con una lámina que imaginamos intenta representar lo más característico o "extraño" del grupo escogido. El grabado que nos interesa ilustra el último capítulo del libro, que tiene como título Fuegian Dwarfs, o sea, Enanos Fueguinos (Mayne Reid, 1860, pp. 425-445). Este título tiene que leerse como una referencia opuesta al nombre de otro capítulo dedicado a los "patagones", Patagonian Giants, es decir, Gigantes Patagones (Mayne Reid, 1860, pp. 397-422).

La firma que aparece en la esquina inferior

7 Johann Baptist Zwecker nace en Frankfurt el 18 de septiembre de 1814. Estudia arte en Dusseldorf $y$ Frankfurt. Se establece en Londres alrededor de 1850. Se hizo bastante conocido por su trabajo artístico en libros de historia natural tales como The Geographical Distribution of Animals de Alfred Russell Wallace, publicado en 1869, y Popular Natural History de John George Wood, publicado en 1871. Muere el 10 de enero de 1876 en Londres (Engen, 1985). izquierda del grabado revela la identidad del artista: se trata de J. B. Zwecker ${ }^{7}$, muy conocido por su trabajo como ilustrador de revistas, libros para niños/as, relatos de aventuras y textos de historia natural. Zwecker es también el autor de las diez ilustraciones que acompañan el libro At home with the Patagonians escrito por George Ch. Musters. Estos dibujos le llevaron a decir que "el hábil lápiz ha creado de simples esbozos dibujados en una libreta de bolsillo, las vívidas y fieles ilustraciones que traen ante sus ojos el paisaje y los incidentes de la vida en la Patagonia" (Musters, 1871, p. viii). El grabado fue elaborado, como lo indica la firma en la esquina inferior derecha, por Dalziel Brothers ${ }^{8}$, una importante familia inglesa de grabadores sobre madera. La imagen es recogida en uno de los más importantes catálogos de dibujos y grabados

8 La empresa Dalziel Brothers fue fundada en 1840 por los hermanos George y Edward Dalziel, en Londres. En 1860 se incorpora a la firma su hermano menor Thomas Dalziel. Fueron proveedores relevantes de ilustraciones para libros y revistas del período victoriano medio. La compañía se cierra en 1905 (Engen, 1985). Sus trabajos se encuentran en algunos de los museos más importantes del mundo como el Victoria \& Albert Museum, de Londres. 
relacionadas con ballenas y balleneros, con un notable comentario: "representa una inusual pero práctica manera de conducir los bloques de tocino de ballena a tierra firme" (Ingalls, 1987, p. 64).

\section{RELATANDO LA COSTUMBRE}

El capítulo Fuegian Dwarfs contiene un breve relato que describe textualmente la "costumbre" que el grabado representa visualmente:

Cuando una de estas ballenas se encuentra muerta en la playa -pues no tienen la habilidad ni el coraje para capturarla- el afortunado accidente genera entre ellos una temporada de regocijo. Si sólo puede ser alcanzada por agua, en una flota de canoas reman juntos hacia el lugar, si está en tierra, toda la comunidad llega a pie, hombres, mujeres y niños. En una hora o dos, regresan a sus aldeas, cada uno con un gran 'pedazo' de tocino aleteando sobre sus hombros y la cabeza arriba, emergiendo a través de un agujero cortado en el centro de la pieza, como un ranchero mexicano usa su 'sarape' o un habitante de las pampas su 'poncho' de lana. Una fiesta sigue a esta singular procesión (Mayne Reid, 1860, p. 442).

El grabado fue reimpreso en una obra escrita por el novelista W.H.G. Kingston ${ }^{9}$, publicada en Londres en 1879 con el título Kidnapping in the Pacific. The Adventures of Boas Ringdon: A long four-part Yarn (Kingston, 1879a). El grabado titulado Natives carrying off whale flesh [Nativos llevando carne de ballena] ilustra un texto que dice:

Mientras estábamos en la costa, una ballena varó cerca de la boca del puerto. La noticia se difundió y se veían venir canoas

9 William Henry Giles Kingston nace en Londres el 28 de febrero de 1814. Fue un destacado escritor de novelas juveniles entre las que se cuentan varias con temas balleneros tales como Peter the Whaler (1852), The south sea whaler (1875) y The two whalers (1879b). Tradujo al inglés varias obras de Julio Verne. Muere en Middlesex el 5 de agosto de 1880 . desde todas las direcciones. En poco tiempo las canoas se reunieron en torno al cuerpo del monstruo y los pequeños muchachos cobrizos no tardaron mucho en cortar la grasa con sus cuchillos de concha. El agua era poco profunda entre el lugar donde estaba la ballena y la costa, y cuando uno de ellos hubo cortado un pedazo grande de la grasa de la ballena, hizo un agujero en el medio a través del que puso su cabeza, $y$ así llevó su carga a tierra, mascando un pedazo de grasa cruda en el camino (Kingston, 1879a, p. 24).

El mismo grabado fue publicado en 1882 en la revista de la South American Missionary Society ${ }^{10}$, acompañado (o acompañando) un breve relato que dice:

el gran banquete fueguino tiene lugar cuando uno de estos [leviatanes=ballenas] queda varado en la orilla. Todas las personas que se encuentran cerca llegan al lugar, mientras que flotillas de canoas rodean el monstruo encallado, su cuerpo se cubre con pequeños hombres de color cobre, que destazan la grasa con sus cuchillos de concha. Cada uno corta la mayor cantidad posible, y cuando ha arrancado y cortado un trozo grande de grasa, hace un agujero en el centro y pone su cabeza a través de la abertura, lo que deja las manos libres para llevar más del codiciado alimento (The Fuegian Feast, 1882, p. 239).

El conjunto de estas descripciones nos proporcionan un relato bastante coherente sobre "la costumbre"; sin duda, no son relatos independientes, tienen una serie de temas comunes. Por ejemplo, en la segunda y el tercera se indica que los nativos son "gente cobriza" que usa "cuchillos de concha" para cortar la grasa de

10 La South American Missionary Society fue una sociedad misionera anglicana fundada en 1844 que, si bien tuvo contactos con los distintos pueblos originarios de FuegoPatagonia, concentró su labor entre los yaganes y por tanto la mayoría de sus notas "etnográficas" se atribuyen a este grupo (Mann, 1968) 
la ballena, temas que no aparecen en la primera descripción. Sólo en ésta se dice que los nativos llevan los pedazos de grasa "como los habitantes de las pampas su poncho de lana"; sólo en la segunda, que mascan "un pedazo de carne cruda en el camino"; y sólo en la tercera, que "les deja las manos libres para llevar más del codiciado alimento". En la descripción original se dice que "una fiesta sigue a esta singular procesión", asunto que no es recogido en las siguientes.

Un dibujo algo simplificado del grabado fue publicado como ilustración en la obra de Giacomo Bove (1883, pp. 130-131), el mismo aparece incluido en el último trabajo de Chapman (2012, p. 83). Si bien tanto Bove como Chapman se refieren al aprovechamiento de las ballenas por los yaganes, no se detienen a comentar el grabado. Es solamente una ilustración.

Es interesante mencionar la transformación que tiene en el tiempo de la leyenda que acompaña al grabado. En 1860 era Enanos fueguinos (Mayne Reid, 1860, p. 424), en 1879 es Nativos llevando la carne de ballena (Kingston, 1879a, p. 24) y en 1883 se transforma en Una fiesta fueguina (Bove, 1883, pp. 130-131). Más de un siglo después la leyenda que tiene el grabado es El banquete de ballena (Chapman, 2012, p. 83). Sin duda cada uno de los nombres refleja y habla del espíritu de su época.

La imagen transita desde la representación de un grupo exótico, unos curiosos "enanos fueguinos", a una descripción bastante neutral, "nativos llevando carne de ballena", y luego a una práctica peculiar, una "fiesta fueguina". Finalmente termina como ilustración, en un texto etnográfico moderno, de una costumbre culinaria generalizada.

El tema de los contextos de circulación de ciertas representaciones ha sido abordado por Peter Mason (2001) cuando estudia la "vida de las imágenes" y como éstas se desplazan en el tiempo $y$ en distintos soportes visuales gracias a diversas estrategias de representación, tanto a nivel de la propia imagen como en el discurso escrito. Podemos observar que el espacio visual contenido en el grabado se transforma en un espacio semántico en virtud de la relación que establece con el texto que lo acompaña (Alvarado \& Giordano, 2007). En la construcción de esta imagen, sobre la costumbre de los fueguinos de aprovechar partes de una ballena y trasladarlas de una forma específica, se conjugan elementos visuales y textuales que permiten su apropiada circulación.

\section{DESCRIPCIÓN ICONOGRÁFICA}

Panofsky (1984) establece una tríada de niveles de interpretación para el estudio de las relaciones entre la imagen y su significado. En este caso nos ubicamos en lo que llamó el nivel iconográfico, que considera los diferentes componentes que dan sentido a una representación visual. De esta manera, en el grabado podemos distinguir tres planos que intentaremos aislar y describir ordenadamente (Fig. 2). En el primer plano se observa, en tierra, una persona adulta con dos niños/as llevando sobre sus hombros unos bultos, trozos de carne/grasa; un poco más atrás se ve otro adulto, también con un bulto sobre sus hombros y con el agua hasta la cintura; completa este plano una persona sentada en unas rocas, saboreando un pequeño trozo de carne/grasa en su boca.

En un segundo plano, hacia la izquierda, hay una ballena varada, rodeada por un grupo numeroso de personas; en la zona de su cola se acumulan, en el agua, varios bultos y algunos individuos están sobre la ballena. Un par de canoas, de doble proa, con dos personas a bordo, navegan hacia ella. Varias figuras humanas se dirigen a tierra llevando sobre sus hombros la misma carga. Tanto hacia la derecha como izquierda del plano, pero un poco más hacia el fondo, se nota la presencia de chozas circulares, columnas de humos y figuras humanas caminando en sus cercanías. Este plano cuenta una historia de izquierda a derecha. En la escena de la izquierda aparece una canoa zarpando. En el centro se representa la llegada de las personas en canoa, el despedazamiento de la ballena y el traslado de los pedazos en los hombros de las personas hacia la costa. En la escena de la derecha se nota la llegada de las personas a la playa con la carga sobre sus hombros.

El plano de fondo corresponde a un paisaje donde este hecho ocurre: una bahía de aguas poco profundas, en un litoral rocoso, en parte cubierto con hielo. El cielo se encuentra nublado, con algunas nubes negras.

El grabado mismo relata una historia. En una pequeña bahía de aguas someras vara una ballena. Mediante señales con humos, la gente 


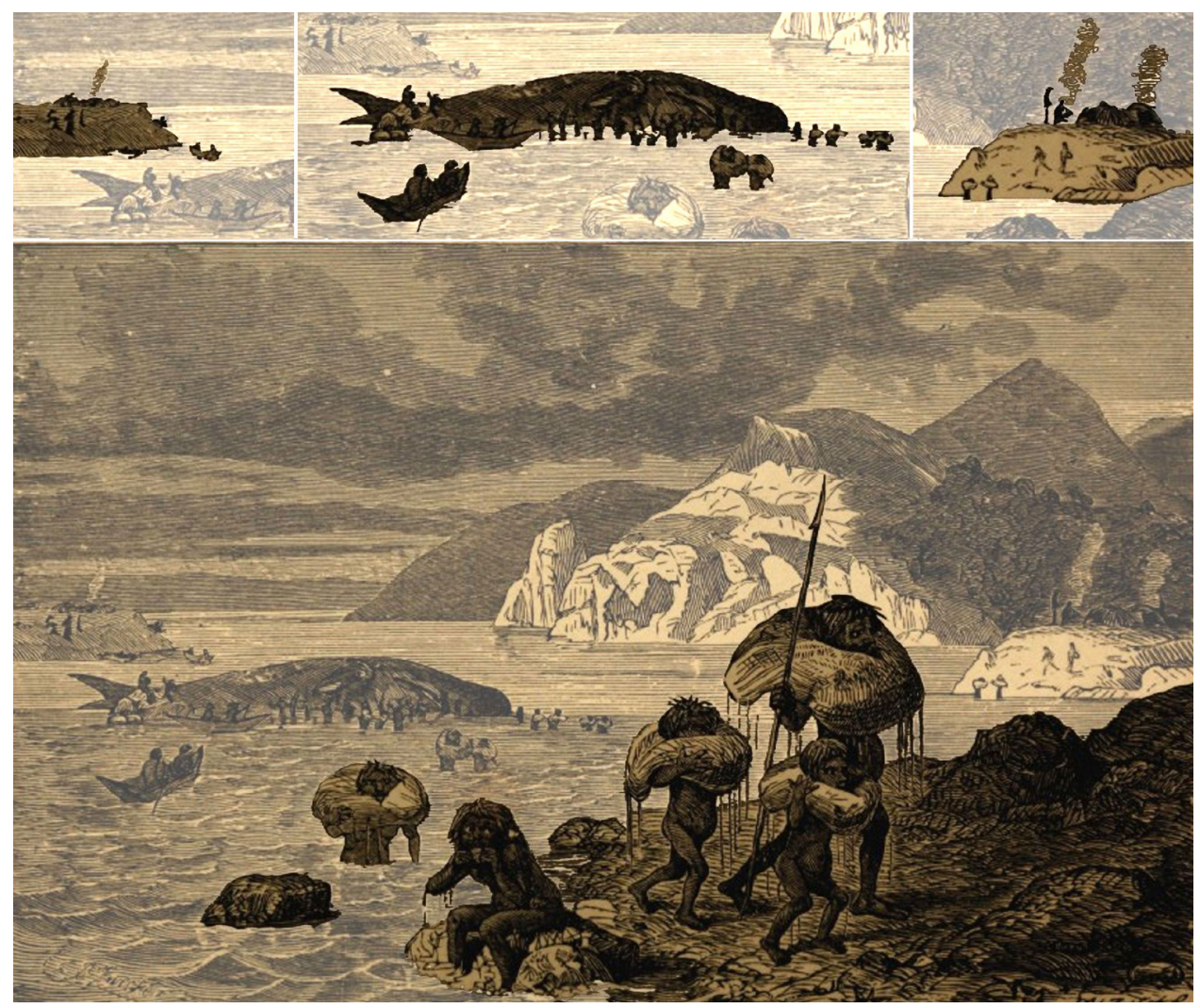

Fig. 2. Planos y escenas: despedazando el grabado. Arriba, las tres escenas del segundo plano; abajo, el primer plano [Intervención de Paula de la Fuente en el grabado de Zwecker].

se entera y numerosas familias se congregan en la costa. Se dirigen hacia la ballena, unos caminando, otros en canoas. Comienzan a cortar trozos de carne y tocino del cetáceo, suponemos con cuchillos de concha, se los colocan sobre los hombros como "ponchos" y se los llevan a tierra, donde han levantado sus chozas. La gente la come en pequeños trozos.

\section{FITZ ROY, DARWIN Y LA COSTUMBRE.}

La "costumbre" la encontramos descrita en los materiales generados por las expediciones del H.M.S. Beagle en las costas fuego-patagónicas, publicados en 1839 en tres volúmenes con algunas ilustraciones (entre las que no se encuentra, por supuesto el grabado en cuestión).

11 Hemos consultado, aparte de la versión original en inglés, una traducción al español reciente del diario, titulada Viajes del 'Adventure' y el 'Beagle'. Diario, publicada en Madrid en 2013 por la editorial Los Libros de la Catarata.
Según nuestras investigaciones la costumbre aparece por primera vez en el segundo volumen de los viajes del H.M.S. Beagle, escrito por Robert Fitz Roy $(1839)^{11}$. En este texto Fitz Roy relata un episodio que le había sucedido al capitán William Low hacía algunos años, cuando estaba con un grupo de unos ciento cincuenta nativos que vivían en los archipiélagos situados al sur del Golfo de Penas ${ }^{12}$. Le cuenta que en un momento determinado se preocupa con la partida de un pequeño grupo pero los que se quedaron "le explican, mediante señas, que regresarán en unos cuatro días con alimentos". El grupo retorna al quinto día y Low observa que "cada hombre llevaba sobre sus hombros, como un poncho, dos o tres grandes trozos de grasa de ballena con un agujero en el medio". La grasa estaba "semi

12 Fitz Roy señala que son chonos (Fitz Roy, 2013, pp. 177180), pero corresponden a los que hoy denominamos kawésqar. 
podrida y parecía que hubiese estado enterrada". En la choza más grande, "un viejo cortaba delgadas rebanadas de los trozos, las freía y distribuía rotativamente entre la gente, pero antes de hacerlo murmuraba, de manera misteriosa, algunas palabras sobre cada pedazo, mientras que el resto mantenía estricto silencio". Una rebanada "le fue ofrecida a Low". El capitán Low le indica a Fitz Roy que Bob, un muchacho nativo "chono" capturado como represalia por un robo sufrido en los canales patagónicos, observó indicios que sugerían un varamiento de una ballena, entonces, "tomando un palo afilado, sondeó la arena en varios lugares, y encontró muchas piezas grandes de grasa, que fueron llevadas a bordo y derretidas para obtener aceite" (Fitz Roy, 1839, p. 195).

Los datos que Low suministra no son utilizados por Darwin en la primera versión de su diario, es decir, el tercero de los volúmenes de los viajes del H.M.S. Beagle (Darwin, 1839), probablemente porque "la costumbre" ya estaba informada en el segundo volumen (Fitz Roy, 1839). Sin embargo, Darwin incluirá una descripción en la segunda edición de su relato, publicado en Londres en $1845^{13}$. Darwin (1845) señala que:

Cada hombre llevaba una pieza cuadrada de grasa de ballena pútrida, con un orificio en el medio a través del que sacaban sus cabezas, como los gauchos lo hacen con sus ponchos o mantas. Tan pronto la grasa era llevada a una choza, un anciano la cortaba en delgadas rebanadas y murmurando sobre ellas, las freía por un minuto y las distribuía entre el hambriento grupo, que mantenía un profundo silencio [...] cada vez que una ballena era arrojada a la playa, los nativos enterraban grandes trozos de ella en la arena, como un recurso en tiempos de hambruna (p. 214).

Destaca además que cuando "descubrían la carcasa flotante de una ballena pútrida, era

13 Este libro fue traducido al español como Viaje de un naturalista alrededor del mundo y publicado por primera vez en Madrid en 1899 por la editorial La España Moderna. Ediciones posteriores llevan el título de Diario del viaje de un naturalista alrededor del Mundo en el navio de una verdadera fiesta, y ese miserable alimento era acompañado por unos pocos frutos $y$ hongos desabridos" (Darwin, 1845, p. 213). Es importante señalar que aunque Darwin recorrió la zona e interactuó con los fueguinos, no observó esta "costumbre". Como él mismo lo indica, la información le habría sido proporcionada "por Mr. Low, un capitán lobero, íntimamente familiarizado con los nativos de esta región, quién me ha entregado un curioso informe del estado de un grupo de ciento cincuenta nativos que viven en la costa occidental" (Darwin, 1845, p. 213).

La información proporcionada por Fitz Roy y Darwin se inserta dentro de un profundo cambio en los paradigmas que orientan el saber de los siglos XVIII y XIX, surgiendo la historia natural como una estructura de conocimiento que implica desarrollar un método científico para aproximarse al estudio de la flora, la fauna y los grupos humanos, predominando el realismo y la intención de clasificar todo lo observado en un sistema ordenado: "los sistemas clasificatorios del siglo XVIII generaron la tarea de ubicar a cada especie en el planeta, sacándola de su entorno particular y arbitrario (el caos) y colocándola en un sitio adecuado dentro del sistema (el orden: libro, colección o jardín) con su nuevo nombre europeo, secular y escrito" (Pratt, 2010, p. 71).

No sólo se incorporan dentro de la historia natural descripciones textuales de las especies sino también una serie de parámetros visuales para su clasificación: número, forma, posición y tamaño relativo. Tal vez sea esta la razón por la que tanto en las descripciones de viajes como en los estudios de los naturalistas aparecen sistemáticamente imágenes de plantas, de animales y de "tipos humanos". En estas expediciones participaban personas provenientes de diferentes ámbitos (mineralogía, geografía, botánica, zoología, etc.) y se incorporaron también dibujantes que documentaban visualmente todo lo encontrado en estos viajes.

En los relatos de Fitz-Roy y de Darwin se incluyen varias imágenes, entre ellas algunas

S.M. Beagle (1921-1922, Madrid, Calpe). Como control de nuestra traducción del original en inglés consultamos la versión publicada con el título de Viaje de un naturalista alrededor del mundo en 1945 por la Librería El Ateneo de Buenos Aires. 

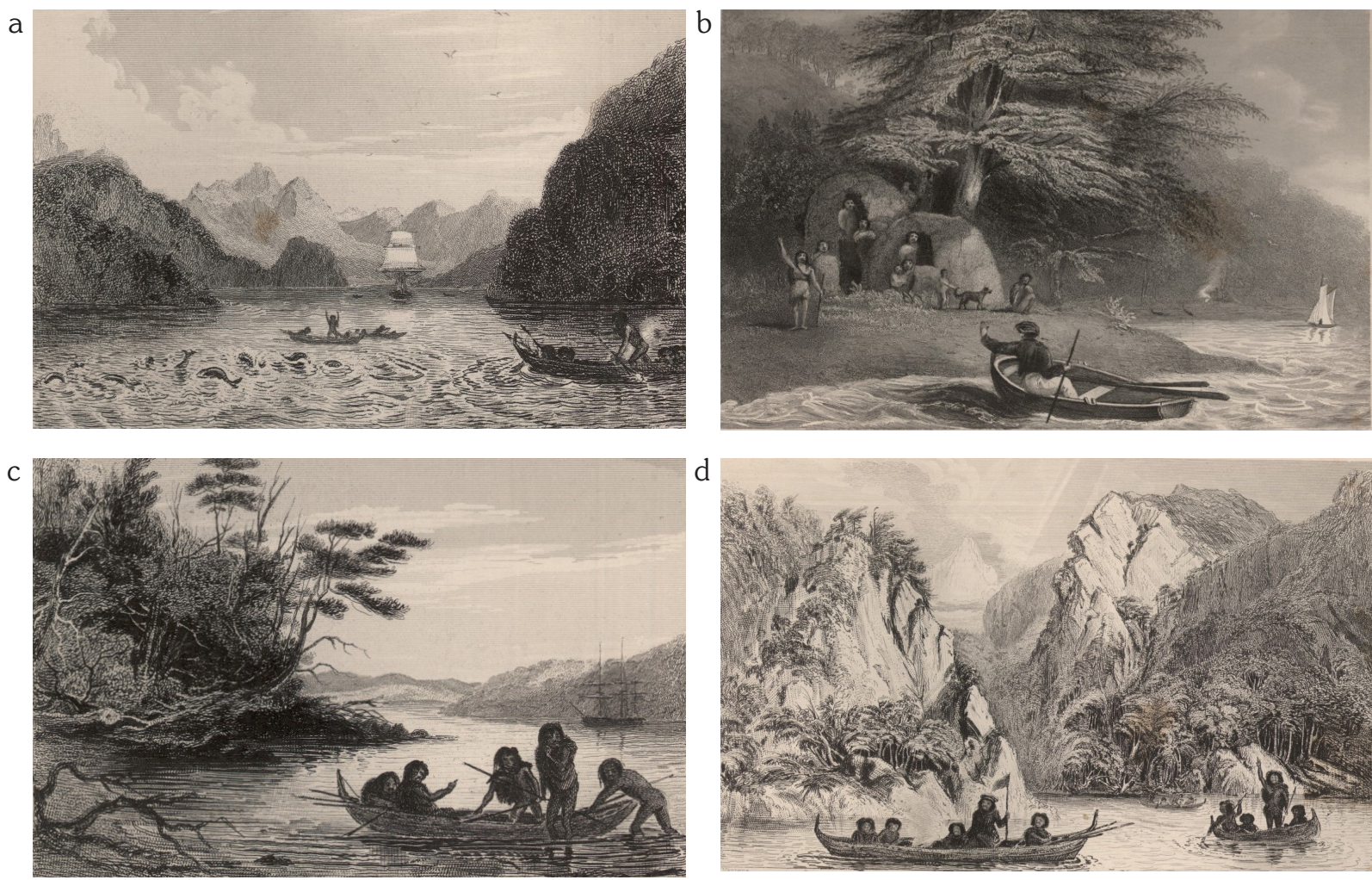

Fig. 3. a: Estrecho Narrow, Canal Beagle [En Fitz Roy, R. 1839; grabado de Conrad Martens \& Thomas Landseer]; b: Chozas Fueguinas en Puerto Esperanza en el Canal Magdalena [En Fitz Roy, R. 1839; grabado de Ph. Parker King \& S. Bull]; c: Ensenada en el Canal Beagle [En Fitz Roy, R. 1839; grabado de Conrad Martens \& Thomas Landseer]; d: Isla Button, cerca de Wulaia [En Fitz Roy, R. 1839; grabado de Conrad Martens \& Thomas Landseer].

relativas a los nativos fueguinos. En la segunda travesía del Beagle (1831-1836) formaba parte de la dotación el dibujante y acuarelista Conrad Martens ${ }^{14}$ pero no todos las imágenes son suyas (Fig. 3). Lo que nos interesa destacar acá son ciertas similitudes entre el grabado de Zwecker y algunos de los dibujos generados por la expedición del Beagle, sobre todo la forma como se dibujan los nativos, las canoas y las viviendas. Seguramente Zwecker no sólo leyó los textos de Fitz Roy y Darwin, sino también observó las imágenes para construir su relato visual.

\section{LA MISMA COSTUMBRE, EL MISMO ESCRITOR, OTROS GRABADOS}

Está meridianamente claro que ni el escritor

14 Conrad Martens nace en Londres en 1801. Ilustrador y afamado acuarelista, estudió en Londres con C. Fielding. Luego de su participación en la expedición del Beagle, se ni el ilustrador del grabado original observaron, de primera mano, los eventos que describen ¿Cuál es la fuente de información que permite crear estas descripciones? La respuesta se encuentra en el último libro escrito por Mayne Reid, Land of Fire: a tale of adventure, publicado en 1885, dos años después de su muerte. Mayne Reid nombra repetidamente a los miembros de la expedición del H.M.S. Beagle y cita profusamente las observaciones de Darwin sobre los fueguinos, lo que permite pensar que la información utilizada para construir el relato de 1860 proviene de las mismas fuentes, aunque no exista en Odd People una referencia explícita a ello.

En Land of the Fire, Mayne Reid se refiere brevemente a la costumbre de llevar trozos de grasa de ballena sobre los hombros, cuando relata

establece en forma definitiva en Sydney, Australia, donde fallece el 21 de agosto de 1878 (Lindsay, 1920). 
a

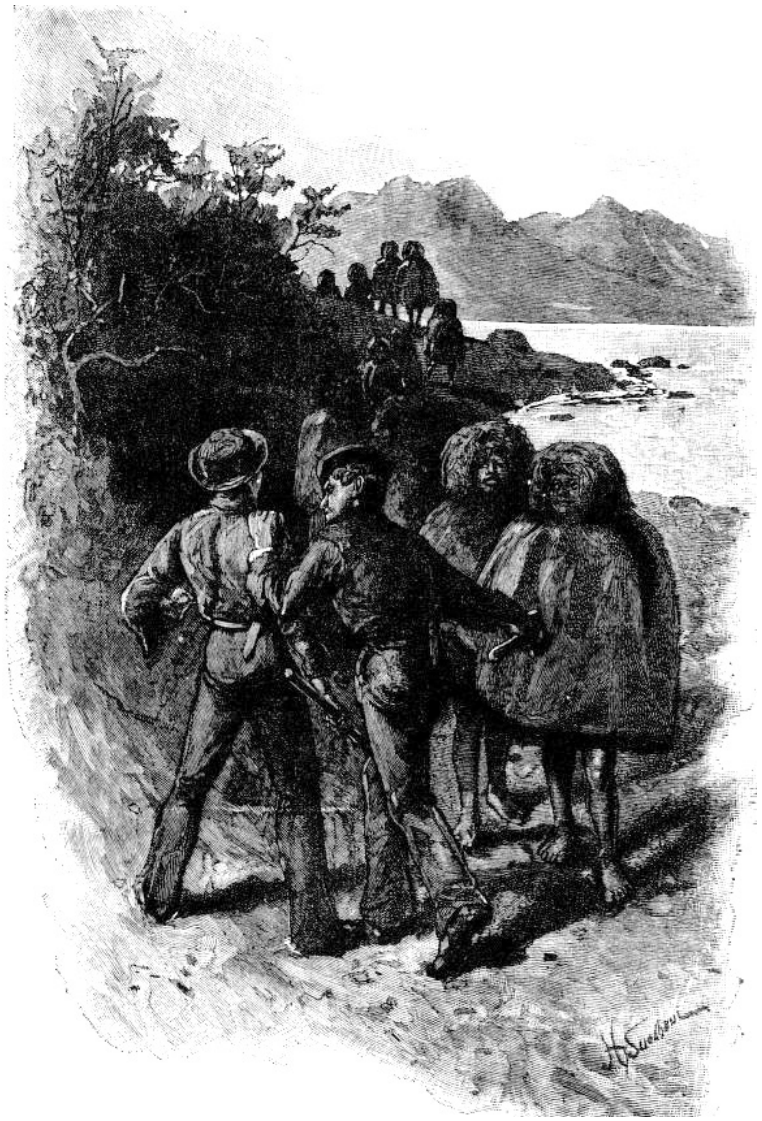

b

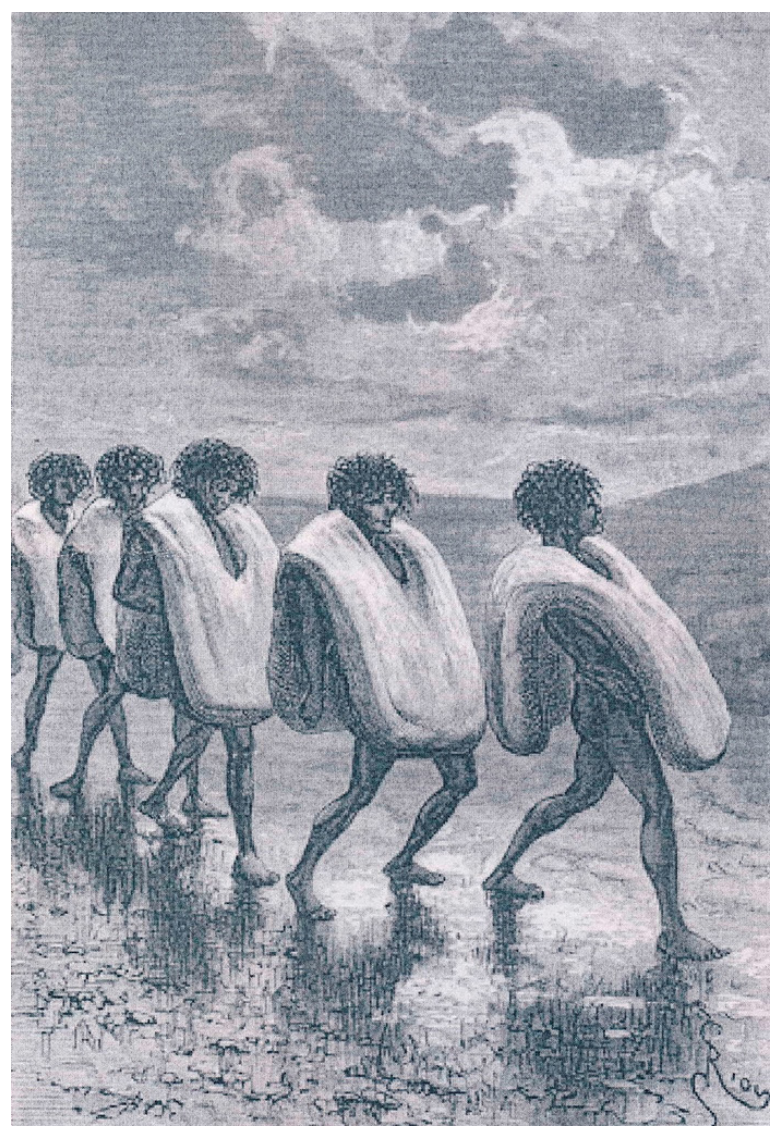

Fig. 4. a: "Una extraña procesión" [En Mayne Reid, 1885a, p.197; grabado H. Sandham]; b: "Pasan su cabeza por un gran pedazo de grasa de ballena" [En Mayne Reid, 1885b, pp. 186-187; grabado de E. Riou].

el encuentro de un grupo de hombres blancos con una partida de fueguinos:

En el camino de la playa, [los nativos] se ven obligados, por la estrechez de la vía, a marchar en fila india como eslabones de una larga cadena. Pero ni siquiera cuando vienen más cerca y se distinguen mejor parecen seres humanos. Tienen algo como cabezas humanas, pero no tienen cuello y de hecho las cabezas están hundidas entre los hombros, que son de enorme amplitud $y$ continúan en gruesos cuerpos sin brazos, con piernas cortas y delgadas por abajo. A medida que avanzan a lo largo de la playa, a un ritmo lento, en una rara procesión como de ogros, los blancos quedan, por un momento, completamente desconcertados sobre lo que pueden ser. Nada se puede decir hasta que estén más cerca. Entonces se ve que después de todo son seres humanos -jsalvajes fueguinos, cada uno con un trozo de grasa de ballena sobre la cabeza, que cae por los hombros como un poncho, cubriéndolos hasta casi las rodillas! (Mayne Reid, 1885a, pp. 197-199).

La descripción se sitúa, por supuesto, en el clima creado por Darwin respecto de los fueguinos, dudando incluso de su humanidad. Es necesario acercarse mucho para darse cuenta que son seres humanos. Desde lejos parecen ogros, monstruos, sin hombros ni brazos. Pero el relato es también irónico: la confusión es del hombre blanco que no se da cuenta que lo que deforma el cuerpo de los fueguinos no es más que un trozo de grasa de ballena que llevan sobre sus hombros.

El texto original en inglés tiene una sugerente 
ilustración, dibujada por Henry Sandham ${ }^{15}$ y la traducción francesa otra, realizada por Édouard Riou $^{16}$ (Mayne Reid, 1885a, p. 197; 1885b, pp. 186-187; ver Figs. 4 a y b). Las imágenes "ilustran" la costumbre del traslado de los trozos de grasa sobre los hombros, manteniendo el primer plano del grabado original, pero la ballena y las operaciones sobre ella, es decir, el segundo plano, ha desaparecido, reemplazado por un paisaje.

\section{UNA DISGRESIÓN: RETRATO DE WILLIAM LOW}

El capitán William Low era un lobero escocés que pasó la mayor parte de su carrera en los alrededores de Tierra del Fuego y las islas Malvinas. Era el principal informante de Robert Fitz Roy sobre los habitantes de los canales patagónicos occidentales (Cooper, 1917, p. 9). Las observaciones hechas por el capitán Low y sus relatos lo transforman en un "para-etnógrafo", es decir, uno de aquellos "sujetos expertos, que no son nativos ni colegas sino contrapartes" del etnógrafo (Holmes \& Marcus, 2005, p. 248). Los relatos de Low son equivalentes históricos de las observaciones que hubiesen hecho etnógrafos profesionales. La importancia etnográfica de los testimonios de Low deriva de su experiencia como lobero en los fiordos de los archipiélagos de la Patagonia Occidental Insular y del conocimiento acumulado que tenía de los nativos debido a su larga permanencia en la zona.

El capitán Fitz Roy le compra a William Low en 1832 la goleta Unicorn, re-bautizada como Adventure, y lo contrata como piloto en algunas de las campañas hidrográficas desarrolladas en las costas patagónicas al sur de Chiloé (Chapman, 2012, p. 281). Parte de la información entregada por Low a Fitz Roy y Darwin ha sido bastante controvertida, en especial cuando dice que los fueguinos, "cuando están en guerra, son caníbales",

15 Henry Sandham nace en Montreal, Canadá, el 24 de mayo de 1852. Pintor, ilustrador y fotógrafo, alcanzó gran reputación por sus acuarelas sobre temas canadienses. Sandham produjo ilustraciones para varias revistas muy conocidas en la segunda mitad del siglo XIX, tales como Harper's Weekly, Century Magazine y Saint Nicholas Magazine. Muere en Londres el 21 de junio de 1910 (Landry, 1994, pp. 924-925).

16 Édouard Riou nace en Saint Servant, Francia, el 3 de basándose parcialmente en un relato hecho "por un muchacho que [el capitán Low] había capturado" (Darwin, 1845, p. 214). Chapman discute extensamente este tema, concluyendo que "este error, que los yaganes fueran caníbales, distorsionó la visión que Darwin tuvo de ellos más que ninguna otra impresión que pudieran haberle provocado" (Chapman, 2012, p. 228).

El capitán Low "se encariñó con la húmeda, verde $\mathrm{y}$ apacible tierra chilota que sin duda le recordaría en mucho a su natal Inglaterra, y pasó a radicarse en ella al concluir aquella exploración en 1834. Al cabo de un tiempo se unió con una hija de la noble isla [Carmen Garay], dando origen a un robusto tronco familiar que existe hasta nuestros días" (Martinic, 1980, p. 184). Fallece en Chiloé en 1840 o $1841^{17}$. Sus descendientes radicados en Quellón, Bernardino Bórquez Low, Amanda Low y Amalia Low nos contaron en el año 2008 muchas historias de ballenas y balleneros.

\section{MARTÍN GUSINDE Y LA COSTUMBRE}

En su etnografía sobre los yaganes, Martín Gusinde menciona la costumbre de trasladar trozos de grasa de ballena sobre la cabeza y la describe en forma muy precisa, sin incorporar ninguna imagen. Señala que "todos los habitantes de una comarca celebran con júbilo indescriptible la presencia de una ballena que el mar arrastra hacia la tierra o que encalla en la costa". Normalmente, "los hombres de más edad y ascendiente se ponen de acuerdo con aquel que vio o tocó por primera vez la ballena acerca de quién se hará cargo de desmembrarla". No todos pueden desempeñar esta tarea y se necesita de un verdadero especialista para que "la distribución se haga sin inconvenientes y para que se pierda la menor cantidad de carne y grasa posible". El wálaputës, "como se denomina al hombre diestro en desmembrar una ballena", con cuatro o cinco ayudantes, "emprende la tarea de

diciembre de 1833. Estudió dibujo con Gustav Doré y se hizo conocido por ilustrar varias novelas de Julio Verne, entre ellas Viaje al centro de la Tierra y Veinte mil leguas de viaje submarino. Muere en Paris el 27 de enero de 1900 (Gauthier, 2008).

17 Bernardo O'Higgins lo había propuesto para comandar el buque que ocuparía la zona del estrecho de Magallanes, la goleta Ancud, pero su muerte impidió cumplir con lo recomendado (Martinic, 1980). 
trinchar al animal". Para hacerlo "se colocan junto o encima de la ballena y comienzan a separar con una valva de mejillón afilada trozos de grasa del tamaño de un pequeño tablero de mesa". Quita la piel y desde arriba "practica las incisiones que llegarán hasta el tejido muscular". Desprende "cada trozo de grasa cuadrada por debajo y se lo entrega al primer candidato" pero, "antes de entregar una pieza practica una larga incisión en la parte central de la misma por la cual el receptor introduce la cabeza". De esta manera "el trozo de grasa le colgará del cuello a la manera de un gran collar que le cubre los hombros y con él supera en comodidad la de llevarlo cargado al hombro o en los brazos; así no se puede escapar y a la vez tiene las manos libres". Todos los que asisten "recibirán su trozo de la misma manera y regresarán una vez que lo hayan comido" (Gusinde, 1986, I, p. 558).

Gusinde no indica si tuvo oportunidad de observar "la costumbre" entre los yaganes, si se la contaron o si la información la obtuvo de alguna fuente documental ${ }^{18}$. En su etnografía sobre los kawésqar, sin embargo, transcribe integramente la referencia de Fitz Roy que ya hemos citado (Gusinde, 1991, I, p. 62) y menciona la costumbre cuando habla del consumo de los cetáceos por parte de los nativos: "se cortaba un trozo de lardo, de más o menos un metro cuadrado, del cuerpo del animal muerto y se lo ponían como una golilla sobre los hombros, pasándolo sobre la cabeza, para transportarlo con mayor comodidad" (1991, I, p. 328).

\section{OTRA DIGRESIÓN: MOBY DICK, "PONCHOS", BALLENEROS Y FUEGUINOS}

Robert Fitz Roy, Charles Darwin y Thomas Mayne Reid usan la palabra "poncho" para representar el estilo en que los fueguinos llevaban los trozos de grasa de ballena sobre la cabeza. Fitz Roy dice que la usaban "como un poncho" (1839, p. 195). Darwin señala que la llevaban como "los gauchos lo hacen con sus ponchos o mantas" (1845, p. 214). Mayne Reid indica en uno de

18 En realidad, la información disponible nos indica que Gusinde no observó directamente un varamiento de ballena, por lo que la duda está en si alguien se la contó o bien tomó la información que Low le entrega a Fitz Roy y Darwin.

19 El sustantivo blanket se refiere a una manta, cobija, frazada sus libros que transportaban los trozos de grasa "como un ranchero mexicano usa su 'sarape' o un habitante de las pampas su 'poncho' de lana" (1860, p. 442) y en el otro libro dice que cada trozo de grasa les "cae por los hombros como un poncho, cubriéndolos hasta casi las rodillas" (1885a, p. 199).

Esta frase nos conduce inevitablemente a Herman Melville, que en Moby Dick también usa la palabra "poncho", esta vez para referirse a la capa de grasa que cubre a las ballenas. Dice que la ballena, "está envuelta en una capa de grasa como en una verdadera manta o colcha, o, mejor aún, como en un poncho indio puesto sobre su cabeza y que cae hasta sus extremidades". Agrega que "a causa de esta acogedora cobertura, la ballena puede mantenerse cómoda en todo tipo de clima, en todos los mares, las estaciones y las mareas" (Melville, 1993[1851], p. 192). Esta similitud metafórica entre fueguinos y ballenas, con el poncho cayéndole hasta las extremidades, es notable.

Melville agrega en el mismo capítulo del libro que los balleneros "sacan la grasa [de la ballena] en largos pedazos, llamados blanket-pieces", palabra que "como la mayoría de los términos marinos, es muy acertada y significativa" (1993 [1851], p. 192). Podemos traducir blanket-piece ${ }^{19}$ como "trozos de manta", si consideramos que la manta de la ballena o su "poncho" es toda su grasa. Los trozos de manta, de 20 pies de largo, 8 pies de ancho y con un peso aproximado de una tonelada, se subían a cubierta (Fig. 5), donde eran divididos en trozos más pequeños, llamados horse-pieces, o "trozos de caballete" 20 y luego en otros aún más pequeños, del tamaño de un libro, llamados bible-leaves u hojas de biblia. Estos pedazos se echaban en las calderas situadas en cubierta para producir el aceite que era envasado en barriles (Creighton, 1995, p. 68).

Los balleneros de Melville y centenares de balleneros ingleses, norteamericanos y franceses recorrerán desde fines del siglo XVIII las costas sudamericanas occidentales en busca de cachalotes y ballenas jorobadas, siendo el año 1792 "la

o capa. El verbo to blanket significa envolver o cubrir completamente.

20 Recibían ese nombre debido a que eran del tamaño adecuado para ser procesados en "el caballete de picado" o mincing horse, desde donde salían las "hojas de biblia". 


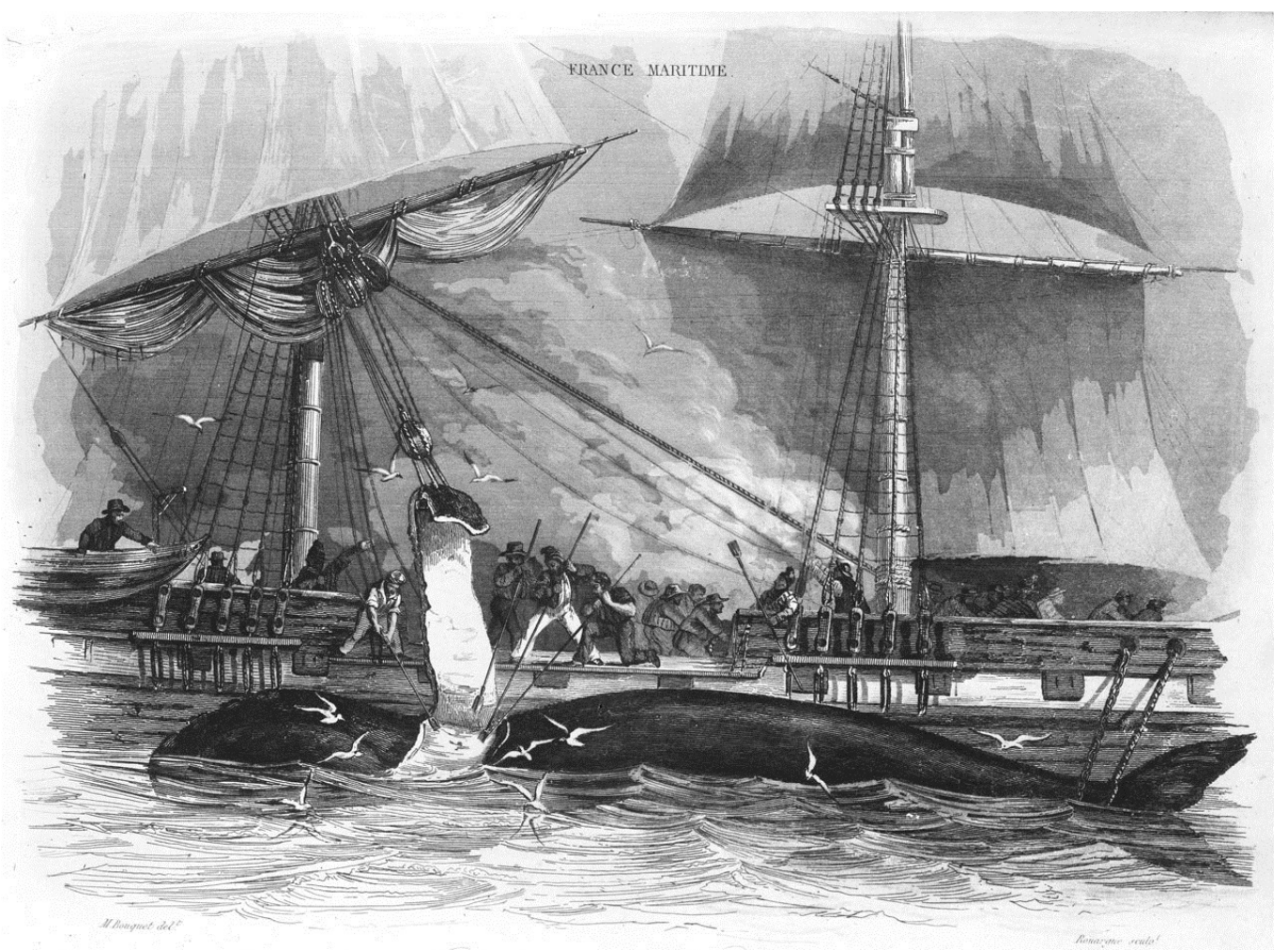

Fig. 5. Despiece de una ballena y la extracción de los "trozos de manta". [En Dépécement de la baleine, 1837, p. 221; grabado de Michel Bouquet \& Emile Rouargue].

apertura de un ciclo ballenero, audaz y renovador" (Pereira Salas, 1971, p. 41). Muchos de estos animales heridos se les escapaban y algunos de ellos iban a morir cerca de las playas que recorrían los fueguinos en los archipiélagos meridionales. George P. Despard (1863), misionero anglicano, cuenta que

El ballenero, a menudo sin intención, es un amigo de [los yaganes], al matar leviatanes y permitir que su cadáver flote a merced de los vientos y las olas, confortuna al menos para los fueguinos ya que trae el enorme cadáver a sus costas y los provee de una dieta abundante y sana, si no apetitosa (p. 680).

Estos eventos permiten enlazar el aprovechamiento de las ballenas por los fueguinos con las innumerables incursiones de balleneros extranjeros cerca de sus costas tanto en el siglo XIX como en los inicios del XX y se puede plantear que existió una relación no intencional bastante estrecha entre balleneros y fueguinos.

Sin embargo, la aparente "simbiosis" tiene su lado oscuro. Las operaciones balleneras, tanto clásicas como modernas (Quiroz, 2014, 2015) impactarán severamente en el número de ballenas antárticas. Chapman señala que la "durante este primer período de caza de ballenas y lobos marinos (entre 1790 y 1829), la matanza de animales marinos en la zona del Cabo de Hornos fue tan devastadora que los animales nunca recuperaron en absoluto sus poblaciones originales" (2012, pp. 100-101).

Con el advenimiento de la caza moderna, a comienzos del siglo XX, este proceso se acentuó, como lo nota uno de sus conspicuos visitantes:

Antiguamente las ballenas eran abundantes en el canal Beagle $y$ en las aguas más al sur, pero desde el establecimiento de las plantas balleneras en las Georgias del Sur, hace algunos 
años atrás, han llegado a ser muy raras. Durante la visita del autor al canal Beagle, el suministro de barbas de ballena se había terminado, y se decía que habían pasado cuatro años desde que una ballena había varado (Lothrop, 1928, pp. 150-151) ${ }^{21}$.

En este mismo sentido, resume Gusinde,

"debe imputárseles a los pescadores de ballenas europeos el hecho de que estos gigantes del océano, antaño tan numerosos, hayan sido casi completamente exterminados en la región del Cabo de Hornos" (1986, p. 500).

\section{UN FINAL}

El relato Darwin-Fitz Roy-Low es utilizado por Mayne Reid para construir su propio retrato de los pequeños fueguinos y su escrito inspira la obra visual de Zwecker. Sin embargo, el relato Darwin-Fitz Roy-Low solo se refiere a la parte final de la historia que cuenta Mayne Reid y, por supuesto, el grabado. Es lo que Low pudo observar con sus propios ojos. Imaginamos que el resto de la historia registrada en el grabado se construye con fragmentos de otros textos que circulaban en esa época (ver Cooper, 1917). La mayor parte de las fuentes consultadas no registra la costumbre de llevar el tocino sobre los hombros como un "poncho", excepto Gusinde, y las fuentes que hemos revisado y citado en extenso tienen probablemente un mismo origen: el testimonio de William Low.

El grabado recoge lo que Low observa (el primer plano) pero lo contextualiza relatando una historia gráfica (el segundo plano) inscrita en un paisaje (el escenario).

El aprovechamiento de las ballenas varadas es un recuerdo que acompañará a yaganes y kawésqar durante toda su vida. Los testimonios de Rosa Yagán (Stambuk, 2011, p. 22), Rosa Clemente, Úrsula y Cristina Calderón (Chapman, 2012, pp. 81-82, 84-86), Gabriela Paterito (Acuña, 2013, p. 107) y Celina Llanllan

21 La primera planta ballenera en las Georgias del Sur fue la de Grytviken, construida por la Compañía Argentina de Pesca en 1904 (Basberg, 2004). Luego vendrían las de
(Fernández, 2010), aunque no se refieren a la "costumbre" de trasladar trozos de grasa de ballena sobre sus hombros, son una pequeña muestra de la importancia que tuvieron las ballenas varadas como alimento y fuente de materias primas para los grupos canoeros australes, permaneciendo en su memoria y en los relatos elaborados a partir de sus recuerdos.

\section{AGRADECIMIENTOS}

Este trabajo ha sido escrito en el marco del proyecto Fondecyt $N^{\circ} 1140056$ Una etnografía retrospectiva de la caza de ballenas en las costas de Chile durante el siglo XIX. Nuestra gratitud a Klaus Barthelmess (1955-2011) por mostrarnos el grabado e indicarnos su relevancia. Agradecemos a Denis Chevallay, de Consultora Fuegia \& Co. Ltda., por aportarnos la Figura 4 b. Un reconocimiento a los evaluadores de este artículo por permitirnos mejorarlo.

\section{BIBLIOGRAFÍA}

Acuña, A. (2013). Memoria del pueblo kawésqar a través de una historia de vida. Magallania, 41(1), 99-122.

Alvarado, M. y Giordano, M. (2007). Imágenes de indígenas con pasaporte abierto: Del Gran Chaco a Tierra del Fuego. Magallania, 35(2), 15-36.

Basberg, B. (2004). The shore whaling stations at South Georgia. A study in Antarctic industrial archaeology. Oslo: Novus Forlag.

Bove, G. (1883). Expedición Austral Argentina. Informes Preliminares. Buenos Aires: Instituto Geográfico Argentino.

Bridges, Th. (1987 [1933]). Yamana-English. A dictionary of the speech of Tierra del Fuego. Buenos Aires, Zagier \& Urruty.

Chapman, A. (2012). Yaganes del Cabo de Hornos. Encuentros con los europeos antes y después de Darwin. Santiago: Pehuén Editores.

Comisionado Presidencial para Asuntos Indígenas (2008). Informe de la Comisión Verdad Histórica y Nuevo Trato con los Pueblos Indígenas. Santiago: Gobierno de Chile.

Cooper, J. M. (1917). Analytical and critical bibliography of

Husvik (1907), Stromness (1907), Ocean (1909), Leith (1910) y Prince Olav (1911). 
the tribes of Tierra del Fuego and adjacent territory. Washington: Government Printing Office.

Creighton, M. S. (1995). Rites \& Passages. The experience of American Whaling, 1830-1870. Cambridge: Cambridge University Press.

Darwin, Ch. (1839). Journal of researches into the geology and natural history of the various countries visited by H.M.S. Beagle. Londres: H. Colburn.

Darwin, Ch. (1845). Journal of researches into the natural history and geology of the countries visited during the voyages of H.M.S. Beagle round the world. Londres: J. Murray.

Darwin, Ch. (1945). Viaje de un naturalista alrededor del mundo. Buenos Aires: Librería El Ateneo.

Despard, G. P. (1863). Fireland: or, Tierra del Fuego. The Sunday at Home: a family Magazine for Sabbath Reading, 10(475), 676-680.

Dépécement de la baleine. (1837). La France Maritime, II, Paris: Postel.

Emperaire, J. (1963). Los nómades del mar. Santiago: Ediciones de la Universidad de Chile.

Engen, R. K. (1985). Dictionary of Victorian wood engravers. Cambridge: Chadwyck-Healey.

Fernández, I. (2010). Navegando en las profundidades de una vida ancestral. Punta Arenas: Agrupación Cultural Interdisciplinaria Kajef.

Fitz Roy, R. (1839). Proceedings of the second expedition 1831-1836 under the command of Captain Robert FitzRoy. Londres: H. Colburn.

Fitz Roy, R. (2013). Viajes del 'Adventure' y el 'Beagle'. Diario. Madrid: Ediciones de la Catarata.

Furlong, Ch. W. (1917). Some effects of environment on the Fuegian Tribes. Geographical Review, 3 (1), 1-15.

Gauthier, G. (2008). Édouard Riou, dessinateur : entre le Tour du monde et Jules Verne : 1860-1900. Paris: L'Harmattan

Gusinde, M. (1951). Hombres primitivos en la Tierra del Fuego: (de investigador a compañero de tribu). Sevilla: Escuela de Estudios Hispano-Americanos de Sevilla.

Gusinde, M. (1986). Los indios de Tierra del Fuego. Tomo segundo: Los Yamana. Buenos Aires: Centro Argentino de Etnología Americana.

Gusinde, M. (1991). Los indios de Tierra del Fuego, Tomo tercero: Los Halakwulup. Buenos Aires: Centro Argentino de Etnología Americana

Holmes, D. R., \& Marcus, G. E. (2005). Cultures of expertise and the management of globalisation: towards a refunctioning of ethnography. En A.Ong \& S. Collier (Eds.), Global assemblages: technology, politics and ethics as anthropological problems (pp. 235-252). Oxford: Blackwell.

Ingalls, E. (1987). Whaling prints in the Francis B. Lothrop Collection. Salem: Peabody Museum of Salem.

Kingston, W. H. G. (1851). Peter the whaler; his early life and adventures in the arctic region, and other parts on the world. Nueva York: C.S. Francis \& Co.

Kingston, W. H. G. (1875). The south sea whaler. A history of the loss of the 'Champion, and the adventures of the crew. Londres: Thomas Nelson \& Sons.

Kingston, W. H. G. (1879a). Kidnapping in the Pacific. The Adventures of Boas Ringdon: a long yarn in four lengths. Londres, Routledge \& Sons.

Kingston, W. H. G. (1879b) The two whalers, or adventures on the Pacific. Londres: Society for Promoting the Christian Knowledge

Landry, P. (1994). Sandham. Henry. Dictionary of Canadian Biography, 13(1901-1910), Toronto: University of Toronto Press.

Lazarus, S. (2006). Troubled waters: the changing fortunes of whales and dolphins. Londres: Natural History Museum.

Lindsay, L. (1920). Conrad Martens, the man and its art. Sidney: Agnus \& Robertson Ltd.

Lothrop, S. K. (1928). The Indians of Tierra del Fuego. Nueva York: Museum of the American Indian.

Mann, W. (1968). An unquenched flame: a short history of the South American Missionary Society. Londres: South American Missionary Society.

Martinic, M. (1980). Patagonia de ayer y de hoy. Punta Arenas: Sociedad Difusora Patagonia Ltda.

Mason, P. (2001). Lives of Images. London: Reaktion Books.

Massone, M., \& Prieto, A. (2005). Ballenas y delfines en el mundo selk'nam. Una aproximación etnográfica. Magallania, 33(1), 25-35.

Mayne Reid, T. (1860). Odd people. Being a popular description of singular races of man. Nueva York: Harpers \& Brothers Publishers.

Mayne Reid, T. (1885a). Land of Fire, a tale of adventure. Londres: Frederick Warne \& Co.

Mayne Reid, T. (1885b). La Terre du Feu. Paris: J. Hetzel et Cia.

Melville, H. (1993 [1851]). Moby Dick. Nueva York: Barnes \& Noble.

Musters, G. H. (1871). At home with the Patagonians. Londres: John Murray.

Panofsky, E. (1984). Estudios sobre iconología. Madrid: Alianza.

Pereira Salas, E. (1971). Los primeros contactos entre Chile 
y los Estados Unidos, 1778-1809. Santiago: Andrés Bello.

Piana E. L. (2005). Cetaceans and human beings at the uttermost part of America: A lasting relationship in Tierra del Fuego. En G. Monks (Ed.) The Exploitation and Cultural Importance of Sea Mammals (pp 121137). Oxford: Oxbow Books.

Pratt, M. L. (2010). Ojos Imperiales. Literatura de Viajes y Transculturación. México D.F.: Fondo de Cultura Económica.

Quiroz, D. (2014). Cazadores modernos de ballenas en las costas de Chile (1905-1983). Santiago: Centro de Documentación de Bienes Patrimoniales.

Quiroz, D. (2015). Cazadores clásicos de ballenas en las costas de Chile (1819-1921). Santiago: Centro de Documentación de Bienes Patrimoniales.

Stambuk, P. (2011). Rosa Yagán. Lakutaia Le Kipa. Santiago: Pehuén.

Steele, J. (1978). Captain Mayne Reid. Boston: Twayne.

Swensen, E. F. (2014). Foraging in the Yamana-English Dictionary. Exploring ethnographical sources of Tierra del Fuego and a discussion of their relevance to the archaeological record in the Beagle Channel. Trondheim: Norwegian University of Science and Technology.

The Fuegian Feast (1882). South American Missionary Magazine, 16(10), 239.

Tilly, Ch. (1978) Anthropology, History and the Annales. Review, I (3/4), 207-213. 